\title{
LACTIC ACIDOSIS OCCURRENCE DURING EXERCISES IN THE SMOKE CHAMBER IN A 53-YEAR-OLD FIREFIGHTER WITH NO SIGNIFICANT MEDICAL HISTORY
}

AGATA BRONISZ ${ }^{1}$, MAGDALENA SPYCHALSKA², and MALGORZATA SZAFRAŃSKA ${ }^{1}$

${ }^{1}$ Nicolaus Copernicus University, Toruń, Poland

Ludwik Rydygier Collegium Medicum in Bydgoszcz

Department of Endocrinology and Diabetology, Clinic of Metabolic Rehabilitation

${ }_{2}^{2}$ Public Regional New Hospital in Nakło and Szubin, Nakło, Poland

Department of Internal Medicine

\begin{abstract}
Lactic acidosis is a form of metabolic acidosis with a high anion gap, reduced rate of arterial blood $\mathrm{pH}$ under $7.35 \mathrm{mmol} / \mathrm{l}$, and lactic acid concentration over $7 \mathrm{mmol} / \mathrm{l}$. In the literature we can find some descriptions of the cases of lactic acidosis in patients with severe systemic diseases (cancer, acquired immunodeficiency syndrome, sepsis, diabetes with cardiovascular disease and after organ transplantations). We present the case of lactic acidosis in a patient with no chronic disease a firefighter in whom lactic acidosis has developed during standard exercises in the smoke chamber.
\end{abstract}

Keywords:

Lactic acidosis, Exercise, Smoke chamber

\section{INTRODUCTION}

Lactic acidosis is defined as metabolic acidosis with a high anion gap (over $16 \mathrm{mmol} / \mathrm{l}$ ), decreased blood $\mathrm{pH}$ under $7.35 \mathrm{mmol} / \mathrm{l}$, bicarbonate concentration under $10 \mathrm{mmol} / \mathrm{l}$ and lactic acid concentration increased above $7 \mathrm{mmol} / \mathrm{l}$ [1]. The first record of lactic acidosis appeared in the literature in 1920, and 5 years later Clausen reported that the cause of its occurrence is an increase of lactic acid concentration in serum [2]. In 1976, Cohen and Woods divided lactic acidosis into types A and B [3]. A large increase of lactic acid and hydrogen ions can be detected in patients with excessive production of lactic acid or its reduced processing, or both processes simultaneously. In contrast to hyperglycaemic comas - ketoacidosis and the hyperosmolar nonketotic coma, lactic acidosis is not a specific diabetes complication and is also found in other diseases and pathological conditions. These include conditions involving hypoxia (lactic acidosis type A), such as hemorrhage, acute and chronic respiratory failure, myocardial infarction complicated by pulmonary edema [4]. Lactic acidosis can be also caused by diseases and factors occurring in the hypoxia-independent mechanisms (lactic

Received: October 4, 2013. Accepted: January 9, 2014.

Corresponding author: A. Bronisz, Department of Endocrinology and Diabetology, Ludwik Rydygier Collegium Medicum in Bydgoszcz, Skłodowskiej-Curie 9, 85-094 Bydgoszcz, Poland (e-mail: agabrr@poczta.onet.pl). 
acidosis type B), such as liver diseases (poorer use of lactate in the process of gluconeogenesis), renal diseases (metabolic acidosis, accumulation of biguanides), after alcohol intake (increased $\mathrm{NADH} / \mathrm{NAD}^{+}$ratio that increases the conversion of pyruvate into lactate), as a side effect of intake of certain drugs like biguanides [4,5]. During the metformin therapy, the increase of lactic acid concentration occurs through two mechanisms. On one hand, the drug increases the production of lactic acid by inhibition of oxidative phosphorylation in mitochondria, which increases the conversion of pyruvate into lactate, during the glycolysis process. On the other hand, it impairs disposal of lactic acid in the liver, because it inhibits the production of glucose from lactate in hepatocytes. In patients with type 2 diabetes taking metformin and afflicted by additional conditions, such as impaired kidney or liver function, it may lead to development of lactic acidosis [4,6]. Clinical symptoms of lactic acidosis are nonspecific, they include: a significant weakness, nausea, vomiting, abdominal pain, diarrhea, shock, cardiac arrhythmias, impaired consciousness. The symptoms usually appear suddenly, but in some cases may also arise slowly. On the whole, the general condition of patients is serious, often also because of a disease that leads to lactic acidosis. In additional studies we can find moderately increased or normal glucose levels, decreased blood $\mathrm{pH}$, base deficit under $10 \mathrm{mmol} / \mathrm{l}$, an anion gap that may even exceed $25 \mathrm{mmol} / \mathrm{l}$, hyperkalemia. Lactic acidosis may be accompanied by increased concentrations of ketone bodies, and chlorine serum concentration decrease [4]. The treatment of lactic acidosis should include the following procedures: alkalization by an intravenous infusion of sodium bicarbonate $\left(\mathrm{NaHCO}_{3}\right)$, glucose supply together with intravenous insulin administration and causal treatment, including hypotension and shock management, hypoxia and ischemia prevention, sometimes hemodialysis or hemoperfusion.

The prognosis in lactate comas is very serious; mortality rate is close to $50 \%$ if the cause of lactic acidosis is a chronic intake of biguanide derivatives [5], and reaches up to $80 \%$ when it is due to some other cause [4].

\section{CASE REPORT}

A 53 year old male (body mass index: 29.1) was admitted to the Department of Endocrinology and Diabetology, Collegium Medicum in Bydgoszcz, Nicolaus Copernicus University in Torun, due to significant muscle weakness of the lower limbs manifesting in being unable to gain a vertical body position, which occurred during intense exercises (mandatory physical fitness training tests for fire brigade employees). During history taking, the patient did not report other diseases or intake of any drugs. Occasionally he received medical advice from the primary health care doctor. He smoked about 20 cigarettes a day for 30 years, consumed alcohol 2-3 times a week in an amount of 0.5-1.0 1 of beer, or $50 \mathrm{ml}$ of $40 \%$ alcohol. He had passed with success his earlier fire worker routine examinations, the results spirometry test were normal (forced expiratory volume in $1 \mathrm{~s}\left(\mathrm{FEV}_{1}\right)$ was 3.28 1, i.e. $99 \%$ of the normal value, the ratio of $\mathrm{FEV}_{1}$ to forced vital capacity was $80.6 \%$ ).

On admission, the general condition of the patient was assessed as mid-serious. The patient was awake, conscious, with blood pressure (BP) 80/60 mm Hg, tachycardia of 120/min, tachypnea - 30 breaths/min. Auscultation revealed numerous bilateral dry rales, he had a fever up to $38^{\circ} \mathrm{C}$. Laboratory tests performed on admission revealed: metabolic acidosis - $\mathrm{pH}-6.786 \mathrm{mmol} / \mathrm{l}$ with acid deficiency$29.9 \mathrm{mmol} / \mathrm{l}$, anion gap - $34.5 \mathrm{mmol} / \mathrm{l}$, bicarbonate concentration $\left(\mathrm{HCO}_{3}^{-}\right)-4.7 \mathrm{mmol} / \mathrm{l}$ and the carbon dioxide partial pressure $\left(\mathrm{pCO}_{2}\right)-30 \mathrm{~mm} \mathrm{Hg}$; blood glucose - $244 \mathrm{mg} / \mathrm{dl}$, ketonuria $-15 \mathrm{mg} / \mathrm{ml}$, increased levels of lactic acid in the blood serum - $26.28 \mathrm{mmol} / \mathrm{l}$ (normal range: $0.45-2.0$ ) and creatine kinase - $656 \mathrm{U} / 1$ (normal range: 30-200).

Serum creatinine, amylase, sodium and potassium levels were within normal limits (respectively: $0.9 \mathrm{mg} / \mathrm{dl}$ (norm: 0.6-1.3), glomerular filtration rate $-94 \mathrm{ml} / \mathrm{min} / 1.73 \mathrm{~m}^{2}$ (norm: > 90), $50 \mathrm{U} / \mathrm{l}$ (norm: 25-125), $\mathrm{Na}^{+}-142.7 \mathrm{mmol} / \mathrm{l}$ (norm: 136-145), $\mathrm{K}^{+}-4.52 \mathrm{mmol} / \mathrm{l}$ (norm: $3.5-4.5$ ). Due to the fact that lactic acidosis may complicate acute coronary syndrome, 
in the Admission Room acute myocardial ischemia was excluded - electrocardiography within normal limits, markers of myocardial necrosis twice under the cut-off point of acute coronary syndrome. In addition, during hospitalization, a chest X-ray was performed (the result within the norm), and an ultrasound of the abdomen, which showed enlarged liver (180 mm length) and its increased echogenicity. No lesions were revealed within its range. To search for the features of hepatic injury, the following laboratory tests were carried out: activity of aspartate aminotransferase - AST - 78 U/1 (normal range: 4-34) and alanine aminotransferase - $28 \mathrm{U} / 1$ (normal range: 0-45), gamma-glutamyltransferases (GGT) - 154 U/1 (normal range: 12-64) and INR (International Normalized Ratio) was determined - 0.94 (normal range: 0.9-1.3). The concentration of total cholesterol was $268 \mathrm{mg} / \mathrm{dl}$ (norm: < 200), triglycerides $175 \mathrm{mg} / \mathrm{dl}$ (norm: < 150).

The patient received intravenously $500 \mathrm{ml} 0.9 \%$ sodium chloride and $60 \mathrm{mEq} \mathrm{NaHCO}_{3}$ initially, followed by $1000 \mathrm{ml}$ of $5 \%$ glucose and short-acting insulin administered simultaneously in a pump. In the first hour, a dose of $1 \mathrm{U} / \mathrm{h}$ was used, in the next $5 \mathrm{~h}$ a low flow of $0.5 \mathrm{U} / \mathrm{h}$ was maintained. In addition, the supplementation of potassium chloride was carried out and a low molecular weight heparin in a prevention dose was included. Because of the clinical features of acute bronchitis and slightly increased levels of acute phase proteins $(6.12 \mathrm{mg} / \mathrm{l}$, normal range: $0-5$ ), an empirical antibiotic therapy was included. As a result of the treatment, the patient's general condition rapidly improved. A gradual normalization of acid/base balance was observed. Glycemic profile during intravenous infusion of insulin and 5\% glucose was as follows: 2:30 p.m. $-229 \mathrm{mg} / \mathrm{dl}, 3: 30$ p.m. $-132 \mathrm{mg} / \mathrm{dl}$, 4:30 p.m. - 94 mg/dl, 6:00 p.m. - 102 mg/dl, 8:00 p.m. $82 \mathrm{mg} / \mathrm{dl}$, 9:00 p.m. $-89 \mathrm{mg} / \mathrm{dl}$.

On the second day of hospitalization, the general condition of the patient was assessed as good, BP was $140 / 80 \mathrm{~mm} \mathrm{Hg}$, heart rate $95 / \mathrm{min}$. The control gasometrical examination showed: $\mathrm{pH}$ - $7.431 \mathrm{mmol} / \mathrm{l}$, $\mathrm{pCO}_{2}-29.6 \mathrm{~mm} \mathrm{Hg}$, and base deficit - $3.7 \mathrm{mmol} / \mathrm{l}$, $\mathrm{HCO}_{3}^{-} 19.2 \mathrm{mmol} / \mathrm{l}$. Lactic acid level was $2.6 \mathrm{mmol} / \mathrm{l}$, and fasting plasma glucose $96 \mathrm{mg} / \mathrm{dl}$. The intravenous infusion of insulin and glucose was discontinued. Creatine kinase increased to $11268 \mathrm{U} / \mathrm{l}$. The neurologic consultation revealed no muscle weakness or other abnormalities. During the patient's stay at the clinic, an oral glucose tolerance test with $75 \mathrm{~g}$ glucose (OGTT) was abandoned, because of the clinical features of acute bronchitis; however, $\mathrm{HbA}_{1 \mathrm{c}}$ and $\mathrm{C}$-peptide were determined, and the respective values were: $4.9 \%$ (normal range: 4.8-6) and $1.57 \mathrm{ng} / \mathrm{ml}$ (normal range: 1.1-4.4). Six months after discharge, normal carbohydrate metabolism in OGTT test and bilirubin levels within the normal range were found, but AST (52 U/l) was still elevated.

\section{DISCUSSION}

The literature data shows that lactic acidosis occurs most frequently in cancer patients, especially of the lymphatic system [7], acquired immunodeficiency syndrome treated with reverse transcriptase inhibitors (3.9/1000) [8-11], diabetes treated with metformin (2-9/100 000) [12-15]. The basic disorder of this syndrome is an excessive accumulation of lactic acid in the blood and the occurrence of lactic acidosis. As described in the introduction, this may be a consequence of both excessive production of lactic acid or its limited use, but most often these two processes occur at the same time. Type A lactic acidosis is caused by tissue hypoxia. It may appear as a result of carbon monoxide poisoning, bleeding, heart attack, pulmonary embolism, sepsis, acute pancreatitis, and trauma. In these clinical situations, intense anaerobic metabolism causes the production of significant amounts of lactic acid, exceeding the possibility of acid metabolism. Type A is not characteristic in patients with diabetes. However, since 3/4 of patients with diabetes type 2 die from cardiovascular 
complications, lactic acidosis developing this mechanism may also occur in patients with diabetes, especially type 2 . The increase in the concentration of lactic acid in the blood may also be a result of a lower utilization of this metabolite (lactic acidosis type $\mathrm{B}$, hypoxia-independent). Type $\mathrm{B}$ can be divided into: $\mathrm{B}_{1}$ occurring in systemic diseases (kidney, liver, cancer, diabetes), $\mathrm{B}_{2}$ associated with intake of drugs and chemicals (biguanides, alcohol, zidovudine, salicylates, cyanide, sorbitol) and $\mathrm{B}_{3}$ developing in genetic-conditioned metabolic disorders (deficiency of: glucose-6-phosphatase, fructose-1,6-bisfosphatase, pyruvate carboxylase or pyruvate dehydrogenase).

The anaerobic conversion of glucose occurs mainly in the skeletal muscles, brain, erythrocytes and renal medulla. In its aftermath, lactic acid and hydrogen ion are produced. In the hypoxic conditions also the liver and heart may produce lactic acid. It may be consumed in the process of gluconeogenesis in the liver and kidneys, resulting in glucose production (Corich cycle). This process can only take place in these organs, because the enzymes (pyruvate carboxylase and phosphoenolpyruvate carboxykinase) that catalyze the conversion of glucose into lactic acid can be found only in the liver and kidneys. The conversion of lactic acid to glucose occurs primarily in the liver $-2 / 3$ of the glucose produced in the gluconeogenesis process are formed in this way, whereas only $1 / 3$ of it is produced in the kidneys. Under physiological conditions, the elimination of lactic acid from the blood is fast. Its maximum concentration is observed within 7-13 min after exercise cessation. Usually, after $30 \mathrm{~min}$ of rest it is reduced by $50 \%$ on average and after $60 \mathrm{~min}$ its levels reverse to the values typical for the state of rest.

We decided to present the described case because the fact of severe lactic acidosis occurrence in a patients without significant systemic diseases was surprising. We have failed to locate any similar report in the accessible literature. There is no doubt that in this case, a large amount of lactic acid was produced during intense exercise - the fireman had to make his way through a smoky room while wearing respiratory equipment, and had to perform various tasks (passing through the container, coping with the level difference, opening vertical partitions, moving through the holes, going through a pipe-section, enduring the heat zone). It seems that the skeletal muscle hypoxia occurred due to substantial disparity between the applied load and the local vascular endurance, though the patient had not been treated for any diseases, either cardiovascular or respiratory ones (his spirometry test results were normal). We have made sure that the patient had not taken an active part in fire-fighting actions, had not done exercises regularly. In the fire department he had only been charged with office work. In our opinion, acute respiratory infection and long-term smoking could have also influenced the rapid growth of lactic acid. The high increase of creatine kinase activity, observed in the subsequent days of hospitalization, clearly indicates the replenishment of energy deficiency in skeletal muscle cells with creatine phosphate reserves within them.

It is interesting that a large amount of lactic acid, produced in a short time in skeletal muscles did not become converted into glucose in the gluconeogenesis process occurring in the liver, despite the lack of obvious features of damage to the organ. Although the patient was characterized by a significant overweight, and abdominal ultrasonography showed liver enlargement and traits of liver fatty degeneration, only single indicators of liver enzyme functions were slightly increased. In addition, the patient did not present the features of the metabolic syndrome: he did not have hyperinsulinemia (C-peptide level was normal), and was characterized by sustained reactivity of pancreatic beta cells to glucose stimulus, confirmed by normal value of oral glucose tolerance test (OGTT), did not suffer from high blood pressure. However, we cannot exclude a liver dysfunction, probably related to the excessive alcohol consumption, which corresponds to a lingering AST, moderate increase of GGTP, and increased liver echogenicity. 
In our opinion, the fast improvement in the general condition of the patient after the implemented treatment, was due to the lack of serious diseases of organs involved in the metabolism of lactic acid. The presented case shows, however, that the occurrence of lactic acidosis, a life threatening condition, may take place in patients without clinical features or significant biochemical hepatic, renal, respiratory or cardiovascular dysfunction. This indicates the need of a thorough analysis of the staff qualifications for their ability to work under special conditions. It should be considered whether the routine use of incriminating tests in all employees in specific occupations is justified. It seems that individual approach, taking into account the real nature of ones professional duties, is more appropriate and does not compromise the health and life of workers.

\section{REFERENCES}

1. [Clinical Recommendations of Polish Diabetes Association for the management of patients with diabetes 2013]. Diabetol Klin. 2013;1(Suppl A):26-7. Polish.

2. Clausen SW. Anhydremic acidosis due to lactic acid. Am J Dis Child. 1925;29(6):761-6.

3. Cohen RD, Woods HF, editors. Clinical and biochemical aspects of lactic acidosis. Oxford: Blackwell Scientific Publication; 1976.

4. Czyżyk A. [Pathophysiology and clinical treatment of diabetes]. Warszawa: Wydawnictwo Naukowe PWN; 1997. p. 459-65. Polish.

5. Sieradzki J. [Diabetes mellitus]. 1st ed. Gdańsk: Via Medica; 2006. p. 644-5. Polish.

6. Brown JB, Pedula K, Barzilay J, Herson MK, Latare P. Lactic acidosis rates in type 2 diabetes. Diabetes Care. 1998;21: 1659-63, http://dx.doi.org/10.2337/diacare.21.10.1659.
7. Ruiz JP, Singh AK, Hart P. Type B lactic acidosis secondary to malignancy: case report, review of published cases, insights into pathogenesis, and prospects for therapy. Sci World J. 2011;11:1316-24, http://dx.doi.org/10.1100/tsw. 2011.125.

8. Giola M, Basilico C, Grossi P. Fatal lactic acidosis associated with tenofovir and abacavir. Int J Infect Dis. 2005;9:228-9, http://dx.doi.org/10.1016/j.jiid.2004.09.010.

9. Chattha G, Arieff AI, Cummings C, Tierney LM Jr. Lactic acidosis complicating the acquired immunodeficiency syndrome. Ann Intern Med. 1993;118:37-9, http://dx.doi. org/10.7326/0003-4819-118-1-199301010-00007.

10. Carr A, Cooper DA. Adverse effects of antiretroviral therapy. Lancet. 2000;356:1423-30, http://dx.doi.org/10.1016/ S0140-6736(00)02854-3.

11.Claessens YE, Chiche JD, Mira JP, Soufir L, Rouges P, Goldgran-Toledano D, et al. Bench-to-bedside review: Severe lactic acidosis in HIV patients treated with nucleoside analogue reverse transcriptase inhibitors. Crit Care. 2003;7:226-32, http://dx.doi.org/10.1186/cc2162.

12.Stang M, Wysowski DK, Butler-Jones D. Incidence of lactic acidosis in metformin users. Diabetes Care. 1999;22:925-7, http://dx.doi.org/10.2337/diacare.22.6.925.

13. Biradar V, Moran JL, Peake SL, Peter JV. Metformin-associated lactic acidosis (MALA): Clinical profile and outcomes in patients admitted to the intensive care unit. Crit Care Resusc. 2010;12:191-5.

14.Scale T, Harvey JN. Diabetes, metformin and lactic acidosis. Clin Endocrinol. 2011;74:191-6, http://dx.doi.org/10.1111/ j.1365-2265.2010.03891.x.

15.Peters N, Jay N, Barraud D, Cravoisy A, Nace L, Bollaetr P-E, et al. Metformin-associated lactic acidosis in an intensive care unit. Crit Care. 2008;12:R149:1-5, http://dx.doi. org/10.1186/cc7137.

This work is available in Open Access model and licensed under a Creative Commons Attribution-NonCommercial 3.0 Poland License - http://creativecommons.org/ licenses/by-nc/3.0/pl/deed.en. 